\title{
The effect of phenylephrine on the onset time of rocuronium
}

\author{
Young Ju Won ${ }^{1}$, Yang-Sik Shin ${ }^{1}$, Ki-Young Lee ${ }^{1}$, and Woon Young Cho ${ }^{2}$ \\ ${ }^{1}$ Department of Anesthesiology and Pain Medicine \& Anesthesia and Pain Research Institute, Yonsei University College of Medicine, \\ Seoul, ${ }^{2}$ Department of Anesthesiology and Pain Medicine, National Health Insurance Corporation Ilsan Hospital, Goyang, Korea
}

Background: Several studies have demonstrated that ephedrine shortens the onset time of muscle relaxants, and it does so probably by increasing the cardiac output. However, elevation of the systemic blood pressure through $\alpha$ adrenergic stimulation via ephedrine may affect the onset of muscle relaxants during the induction of anesthesia. We investigated the effect of phenylephrine, which is a selective $\alpha-1$ agonist, on the onset time of rocuronium and the intubating conditions in adults after the administration of propofol.

Methods: Sixty-four patients were randomly assigned to two groups. Phenylephrine ( $0.9 \mu \mathrm{g} / \mathrm{kg})$ (P group) or the same volume of saline (S group) was injected before rocuronium $(0.6 \mathrm{mg} / \mathrm{kg})$ administration. Anesthesia was induced with fentanyl $2 \mu \mathrm{g} / \mathrm{kg}$ and propofol $2 \mathrm{mg} / \mathrm{kg}$. The onset time was defined as the time from the end of rocuronium injection to the time when a single twitch height gets to $0 \%$ or the minimum level. A well-trained anesthesiologist who was 'blinded' to the treatment groups evaluated the intubating conditions. The mean arterial pressure and heart rate were recorded before induction, before intubation, immediately after intubation and 1 minute and 2 minutes after intubation.

Results: The onset time was $84 \pm 18 \mathrm{sec}$ in the P-group and $72 \pm 14 \mathrm{sec}$ in the S-group. There was no difference of the intubating conditions, the mean arterial pressure and the heart rate between the two groups.

Conclusions: A small dose of phenylephrine, which has a limited effect on blood pressure, delayed the onset time of rocuronium after the administration of propofol, and the vasoconstriction effect of phenylephrine may affect the prolongation of the rocuronium onset time at the induction of anesthesia with using propofol. (Korean J Anesthesiol 2010; 59: 244-248)

Key Words: Onset time, Phenylephrine, Rocuronium.

Received: April 1, 2010. Revised: 1st, May 3, 2010; 2nd, June 23, 2010. Accepted: June 24, 2010.

Corresponding author: Yang-Sik Shin, M.D., Department of Anesthesiology and Pain Medicine \& Anesthesia and Pain Research Institute, Yonsei University College of Medicine, 134, Shinchon-dong, Seodaemoon-gu, Seoul 120-752, Korea. Tel: 82-2-2228-2412, Fax: 82-2-363-5847, E-mail: ysshin@yuhs.ac

The 85th Annual Scientific Meeting of The Korean Society of Anesthesiologists, Lotte hotel, Seoul, Korea, 2008.

(c) This is an open-access article distributed under the terms of the Creative Commons Attribution Non-Commercial License (http:// creativecommons.org/licenses/by-nc/3.0/), which permits unrestricted non-commercial use, distribution, and reproduction in any medium, provided the original work is properly cited. 


\section{Introduction}

During the rapid sequence induction of general anesthesia, the use of a muscle relaxant with a rapid onset time and short duration is crucial to reduce the risk of hypoxia and aspiration pneumonia. Although succinylcholine is an excellent choice for the purpose, its many potential complications has led to searching for an alternative. In addition to the development of a new muscle relaxant for rapid tracheal intubation, efforts have been made to use the existing non-depolarizing muscle relaxants by reducing their onset time.

To reduce the onset time, many studies were focused on modifying hemodynamic factors such as the cardiac output, the circulation time and the muscle blood flow [1]. Researchers have suggested that a non-depolarizing muscle relaxant may act more rapidly on the neuromuscular junction through increased cardiac output and muscle blood flow because the agent injected in the vein may reach to the neuromuscular junction more rapidly. Ephedrine was reported by several studies to reduce the onset time of rocuronium, which is a nondepolarizing muscle relaxant, by increasing the cardiac output via the $\beta$-adrenergic receptor [2-5]. On the other hand, esmolol, which is a $\beta$ adrenergic antagonist, was reported to prolong the onset time of rocuronium $[2,5]$.

The above mentioned studies on ephedrine focused on its $\beta$-adrenergic agonist effect. However, ephedrine is a weak, indirect and direct-acting sympathomimetic agent with both $\alpha$ and $\beta$-adrenergic agonist effects. When ephedrine is used after bolus administration of an anesthetic agent, its $\alpha-1$ arteriolar constriction action as well as its $\beta$-adrenergic agonist action prevents hypotension caused by vasodilation and decreased cardiac output. Therefore, the $\alpha$-adrenergic agonist effect of ephedrine may affect the change in the onset time of a nondepolarizing muscle relaxant.
This study was designed to evaluate the effect of an $\alpha$-adrenergic agonist on the onset time of rocuronium by using the direct acting $\alpha$-adrenergic agonist phenylephrine. The changes in the hemodynamic parameters and the duration of rocuronium's action were also evaluated.

\section{Materials and Methods}

This study was approved by the hospital ethics committee and written informed content was obtained from all the patients. Sixty-four patients with an ASA physical status I or II, an age from 15 to 65 years and who were scheduled for elective general surgery were enrolled in this prospective, randomized, double blinded study.

The patients were randomly allocated to either the phenylephrine group (P group) or the normal saline group (S group) using a computer generated randomization list in a sealed envelope. The exclusion criteria included an anticipated difficult airway, pregnancy, a neuromuscular disorder, hypertension, cardiovascular disease and renal disease. Those patients taking drugs that have an influence on phenylephrine or neuromuscular blocking agents and those with known allergy to the drugs used in this study were also excluded. The study syringe containing $5 \mathrm{ml}$ of phenylephrine $0.9 \mu \mathrm{g} / \mathrm{kg}$ diluted with saline $0.9 \%$ (the P-group) or the same volume of normal saline (the S-group) was prepared by an independent researcher. The dose of phenylephrine was based on a previous study that used ephedrine to shorten the onset time of rocuronium, and that study reported $70 \mu \mathrm{g} / \mathrm{kg}$ as the dose that can minimize the adverse cardiovascular effect $[2,4]$. Then the dose of phenylephrine was calculated at the potency ratio of 80 to 1 based on the study by Saravanan et al. [6].

All the patients were fasted for at least $8 \mathrm{hr}$ for solid food and $3 \mathrm{hr}$ for clear fluid. The patients were premedicated with

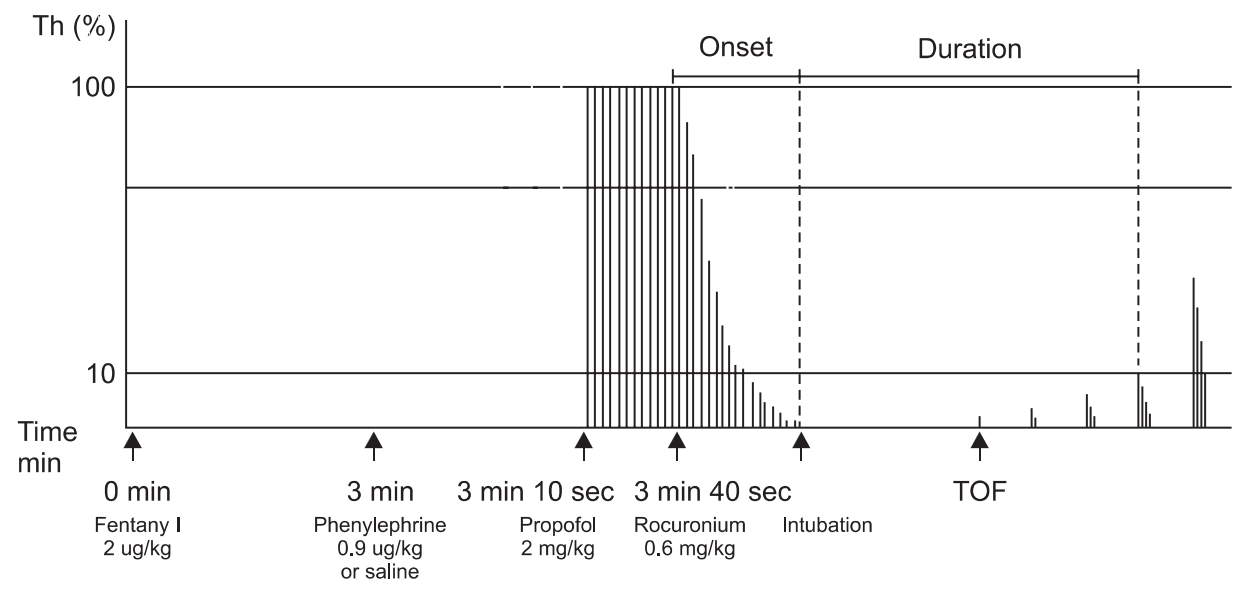

Fig. 1. Schematic diagram of the process of the experiment. Phenylephrine or saline was given 40 sec before the administration of rocuronium. The onset is the time interval from the end of rocuronium injection to $0 \%$ or the maximal depression of a single twitch height. The duration is the time interval from maximal depression of a twitch height to the $10 \%$ recovery of a twitch height. 
midazolam $2 \mathrm{mg}$ by intramuscular injection $30 \mathrm{~min}$ before induction of general anesthesia. On arrival in the operation room, standard monitoring that included ECG, pulse oximetry and non-invasive blood pressure was instituted. All the patients were pre-oxygenated with $100 \% \mathrm{O}_{2}$ for 3 minutes. An intravenous bolus of fentanyl $2 \mu \mathrm{g} / \mathrm{kg}$ was injected and the neuromuscular monitoring was calibrated. The study drug was injected 3 minutes after fentanyl administration and $10 \mathrm{sec}$ after the study drug injection, $2 \mathrm{mg} / \mathrm{kg}$ of propofol was given over $20 \mathrm{sec}$. Rocuronium $0.6 \mathrm{mg} / \mathrm{kg}$ was administered another $10 \mathrm{sec}$ later. Just before the administration of the propofol, neuromuscular monitoring was started with square wave, 1.0 Hz supramaximal single twitch monitoring using TOF-Watch ${ }^{\circledR}$ (Organon Teknica B.V., Boxtel, The Netherlands) on the ulnar nerve of the arm (Fig. 1). The neuromuscular function of the ulnar nerve was assessed using surface eletrodes and the resulting force of contraction of the adductor pollicis longus muscle was continuously measured. The onset time was defined as the time from the end of rocuronium administration to the maximum twitch depression. After the intubation, single twitch monitoring was converted to continuous TOF monitoring and the duration of action was defined as the time from the end rocuronium administration to the $10 \%$ recovery of the $\mathrm{T} 1$ twitch height [7].

The trachea was intubated within $20 \mathrm{sec}$ of $0 \%$ or the maximal depression of the single twitch response. The intubation was performed and assessed by a skilled anesthesiologist who had at least 3 yr experience and who was blinded to the group assignments. The intubation condition was assessed according to the scoring system described by Viby-Mogensen [8] (Table 1). Successful intubation was defined as a successful intubation condition when each score of three components were more

Table 1. Intubation Scoring System According to Viby-Mogensen [8]

\begin{tabular}{cccc}
\hline Score & Vocal cord & Jaw relaxation & Coughing or bucking \\
\hline 3 & Fully abducted & Fully relaxed & Nil \\
2 & Slightly abducted & Slightly stiff & Slight \\
1 & Partially abducted & Stiff & Moderate \\
0 & Closed & Impossible to open & Severe \\
\hline
\end{tabular}

Table 2. Patients' Characteristics

\begin{tabular}{lcc}
\hline & S group $(\mathrm{n}=34)$ & P group $(\mathrm{n}=30)$ \\
\hline Age (yr) [range] & $40 \pm 14[15-59]$ & $40 \pm 13[16-65]$ \\
Weight (kg) & $66 \pm 20$ & $60 \pm 10$ \\
Height (cm) & $161 \pm 19$ & $164 \pm 8$ \\
Gender (M/F) & $11 / 23$ & $10 / 20$
\end{tabular}

Values are means \pm SD or the number. S group: normal saline administered $40 \mathrm{sec}$ before rocuronium, P group: phenylephrine 0.9 $\mu \mathrm{g} / \mathrm{kg}$ administered $40 \mathrm{sec}$ before rocuronium. than 2 points. Failed intubation was defined if any component showed less than 2 points.

Anesthesia was maintained with $2-2.5$ vol\% of end-tidal sevoflurane in oxygen $50 \%$ and air $50 \%$ with positive pressure ventilation that maintained normocapnia. Fentanyl or remifentanyl was administrated supplementary via bolus or infusion. The blood pressure and heart rate were measured immediately prior to administering the study drug (baseline), just before intubation, immediately after intubation and 1 minute and 2 minutes after the intubation.

Statistical analysis was performed using the Statistical Package for Social Sciences statistical software (SPSS 12.0, Chicago, Ohio, USA). Chi-sqaure tests were used for categorical data such as gender or the intubation scoring and paired Student $\mathrm{t}$-tests were used for the other continuous quantitative data. The data are reported as means \pm SDs. The results were considered statistically significant when the P value was less than 0.05 .

\section{Results}

There was no statistical difference in age, weight or height between the groups. However, the number of females was higher than the number of male patients in both groups (Table 2).

The onset time of rocuronium in the phenylephrine group ( $\mathrm{P}$ group) was significantly prolonged (about $17 \%$ ) when compared with that in the saline group (S group) (Table 3 ). The duration of rocuronium were $41 \pm 3$ minutes in the P group and $43 \pm 9$ minutes in the $\mathrm{S}$ group, and there was no significant difference (Table 3). In all the patients, intubation was successful at the first attempt and the intubation score was equal or greater than seven.

The mean arterial pressure was significantly decreased from baseline at just before intubation and at 1 minute and 2 minutes after the intubation (Fig. 2). The heart rate was significantly increased at 1 minute and 2 minutes after the intubation in both groups (Fig. 3). There were no significant differences in blood pressures or heart rates at each time before and after intubation between the two groups (Fig. 2 and 3).

Table 3. Comparison of the Onset Time and the Duration of Rocuronium

\begin{tabular}{lcc}
\hline & S group $(\mathrm{n}=34)$ & P group $(\mathrm{n}=30)$ \\
\hline Onset (sec) & $72 \pm 14$ & $84 \pm 18^{*}$ \\
Duration (min) & $43 \pm 9$ & $41 \pm 3$
\end{tabular}

Values are means \pm SD or the number. Onset: the time interval from the end of rocuronium injection to $0 \%$ or the maximal depression of a single twitch height, Duration: the time interval from the maximal depression of a single twitch to the $10 \%$ recovery of twitch heightfrom the end of rocuronium injection. $S$ group: normal saline administered before rocuronium, P group: phenylephrine $0.9 \mu \mathrm{g} / \mathrm{kg}$ administered before rocuronium. ${ }^{*} \mathrm{P}=0.003$. 


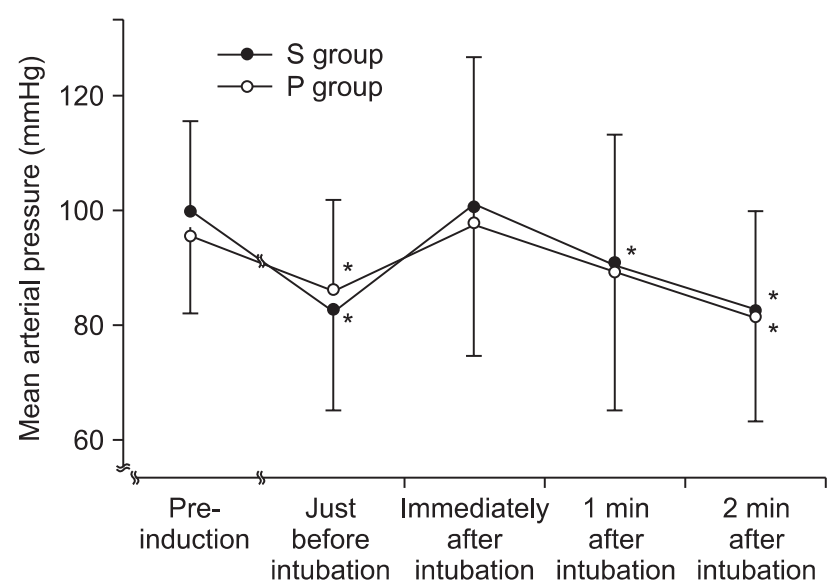

Fig. 2. The changes in the mean arterial pressure during induction. Pre-induction: just before fentanyl injection, $S$ group: normal saline administered before rocuronium, $\mathrm{P}$ group: phenylephrine $0.9 \mu \mathrm{g} /$ $\mathrm{kg}$ administered before rocuronium. ${ }^{*} \mathrm{P}<0.05$ versus the mean preinduction value of the group. Vertical bar: standard deviation.

\section{Discussion}

This study demonstrated that the onset time of rocuronium was prolonged when the patients undergoing general anesthesia were pretreated with phenylephrine. There was no difference in the intubation condition or the duration of action of rocuronium between the two groups.

The onset time of a non-depolarizing muscle relaxant can be influenced by the potency of the agent itself, the injected dosage and circulation factors, which may influence its time course to the neuromuscular junction [1]. When ephedrine was pretreated in the previous studies, the intubating conditions were also improved in addition to reducing the onset time of rocuronium [9-11]. We can suggest the increased cardiac output was a likely cause because ephedrine stimulates the $\beta$-adrenergic accepter, which in turn may have assisted the rapid arrival of the muscle relaxant to the neuromuscular junction [2]. As an indirect evidence, Han et al. [7] reported that the introduction of rocuronium at the point when the cardiac output was increased by ephedrine effectively reduced the onset time. In addition, another study using esmolol, which is a $\beta 1$-adrenergic antagonist, reported that the onset time of rocuronium was delayed when esmolol was introduced before the settlement of rocuronium. These studies support the fact that the effect of a $\beta$-adrenergic receptor agonist oriented by the ephedrine served a significant role in accelerating the onset time $[2,5]$. On the other hand, Herweling et al. [12] reported a debatable result in an animal study. In their study, although the introduction of ephedrine did increase the cardiac output and muscle blood flow, such outcomes failed to affect the onset time of rocuronium. They suggested a possibility that accelerated

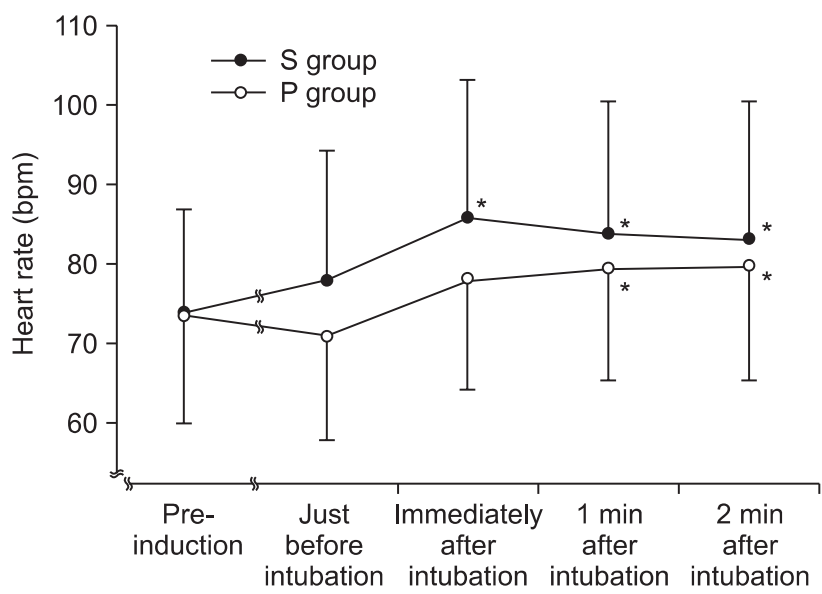

Fig. 3. The changes in the heart rate during induction. Pre-induction: just before fentanyl injection, S group: normal saline administered before rocuronium, $\mathrm{P}$ group: phenylephrine $0.9 \mu \mathrm{g} / \mathrm{kg}$ administered before rocuronium. $* \mathrm{P}<0.05$ versus the mean pre-induction value of the group. Vertical bar: standard deviation.

delivery of $\beta$-adrenergic receptor may not be the only cause of the reduced onset time of a muscle relaxant.

Since ephedrine exerts both $\alpha$-and $\beta$-adrenergic agonist effects, stimulation of the $\alpha$-adrenergic receptors may have influenced the change in the onset time of a depolarizing muscle relaxant by inducing vasoconstriction to increase the perfusion pressure to the organs. Phenylephrine, which is an $\alpha$-adrenergic agonist, increases the blood pressure by contracting the medium-sized peripheral arteries and this maintains the cardiac output [13-15]. The increase in blood pressure caused by phenylephrine increases the muscle blood flow regardless of the contracted arteries [16]. Thus, we can hypothesize that the acceleration of $\alpha$-adrenergic receptor via penylephrine may contribute to the shortening of the onset time of rocuronium. However, in this current study, phenylephrine prolonged the onset of rocuronium and it did not increase the blood pressure. Delayed onset of rocuronium's action may be explained in part with delayed delivery of rocuronium to the neuromuscular junction by the $\alpha$-adrenergic effect of phenylephrine. Another explanation for the delayed onset may be the dose of phenylephrine. The amount of phenylephrine $(0.9 \mu \mathrm{g} / \mathrm{kg})$ used in this study was not sufficient to prevent the decrease in perfusion to the adductor pollicis muscle during anesthesia induction. The dose of phenylephrine was chosen based on a previous study by Saravanan et al. [6], that $0.9 \mu \mathrm{g}$ / $\mathrm{kg}$ of phenylephrine has the same potency as ephedrine $70 \mu \mathrm{g} /$ $\mathrm{kg}[2,4]$, which was reported to cause little change in the blood pressure and heart rate according to the potency ratio of $80: 1$.

The onset time of rocuronium in the phenylephrine group was 84 seconds, which was similar to that in the patients without any pretreatment in other studies $[2,7]$. It is assumed that the 
types or amount of the anesthetic agent used during induction and racial differences may have affected this result. The onset time of rocuronium in the control group was 72 seconds, which was relatively short compared to that in other studies $[4,5,7]$. This result seems to be caused by the higher number of female patients in this study $[17,18]$. There are differences in terms of the pharmacodynamics of the drug used for anesthesia depending on gender and it has been reported that females were $20-30 \%$ more sensitive to muscle relaxant than males $[17,18]$.

There was no difference in the duration of rocuronium or the intubating condition between the two groups in this study. Since the intubation was conducted within $20 \mathrm{sec}$ of the maximum twitch depression under the neuromuscular function-monitoring condition, this outcome was somewhat expected.

There are some limitations to this study. First, the hemodynamic parameters such as cardiac output and systemic vascular resistance, which may ditermine the type of adrenergic effect, were not measured. Second, the muscle relaxation of the adductor pollicis muscle may not exactly reflect the muscle relaxation of the occipitalis muscle and diaphragm, which were related to the intubation.

In conclusion, a small dose of phenylephrine, which has a limited effect on blood pressure, delayed the onset time of rocuronium after the administration of propofol. These results suggest that the $\beta$-adrenergic agonist effect of ephedrine contributes to reducing the onset time of rocuronium by overcomeing the $\alpha$-stimulating effect.

\section{References}

1. Donati F. Onset of action of relaxants. Can J Anaesth 1988; 35 Suppl 1: S52-8.

2. Ezri T, Szmuk P, Warters RD, Gebhard RE, Pivalizza EG, Katz J. Changes in onset time of rocuronium in patients pretreated with ephedrine and esmolol--the role of cardiac output. Acta Anaesthesiol Scand 2003; 47: 1067-72.

3. Gopalakrishna MD, Krishna HM, Shenoy UK. The effect of ephedrine on intubating conditions and haemodynamics during rapid tracheal intubation using propofol and rocuronium. Br J Anaesth 2007; 99: 191-4.

4. Munoz HR, Gonzalez AG, Dagnino JA, Gonzalez JA, Perez AE. The effect of ephedrine on the onset time of rocuronium. Anesth Analg 1997; 85: 437-40.

5. Szmuk P, Ezri T, Chelly JE, Katz J. The onset time of rocuronium is slowed by esmolol and accelerated by ephedrine. Anesth Analg 2000; 90: 1217-9.

6. Saravanan S, Kocarev M, Wilson RC, Watkins E, Columb MO, Lyons G. Equivalent dose of ephedrine and phenylephrine in the prevention of post-spinal hypotension in Caesarean section. Br J Anaesth 2006; 96: 95-9.

7. Han DW, Chun DH, Kweon TD, Shin YS. Significance of the injection timing of ephedrine to reduce the onset time of rocuronium. Anaesthesia 2008; 63: 856-60.

8. Viby-Mogensen J, Engbaek J, Eriksson LI, Gramstad L, Jensen E, Jensen FS, et al. Good clinical research practice (GCRP) in pharmacodynamic studies of neuromuscular blocking agents. Acta Anaesthesiol Scand 1996; 40: 59-74.

9. Belyamani L, Azendour H, Elhassouni A, Zidouh S, Atmani M, Kamili ND. Effect of ephedrine on the intubation conditions using rocuronium versus succinylcholine. Ann Fr Anesth Reanim 2008; 27: $292-6$.

10. Tan CH, Onisong MK, Chiu WK. The influence of induction technique on intubating conditions $1 \mathrm{~min}$ after rocuronium administration: a comparison of a propofol-ephedrine combination and propofol. Anaesthesia 2002; 57: 223-6.

11. Leykin Y, Pellis T, Lucca M, Gullo A. Effects of ephedrine on intubating conditions following priming with rocuronium. Acta Anaesthesiol Scand 2005; 49: 792-7.

12. Herweling A, Latorre F, Herwig A, Horstick G, Kempski O, Gervais HW. The hemodynamic effects of ephedrine on the onset time of rocuronium in pigs. Anesth Analg 2004; 99: 1703-7.

13. Lee A, Ngan Kee WD, Gin T. A quantitative, systematic review of randomized controlled trials of ephedrine versus phenylephrine for the management of hypotension during spinal anesthesia for cesarean delivery. Anesth Analg 2002; 94: 920-6.

14. Lee YH, Clarke KW, Alibhai HI, Song D. Effects of dopamine, dobutamine, dopexamine, phenylephrine, and saline solution on intramuscular blood flow and other cardiopulmonary variables in halothane-anesthetized ponies. Am J Vet Res 1998; 59: 1463-72.

15. Morelli A, Lange M, Ertmer C, Dunser M, Rehberg S, Bachetoni A, et al. Short-term effects of phenylephrine on systemic and regional hemodynamics in patients with septic shock: a crossover pilot study. Shock 2008; 29: 446-51.

16. Banic A, Krejci V, Erni D, Wheatley AM, Sigurdsson GH. Effects of sodium nitroprusside and phenylephrine on blood flow in free musculocutaneous flaps during general anesthesia. Anesthesiology 1999; 90: 147-55.

17. Adamus M, Koutna J, Gabrhelik T, Hubackova M, Janaskova E. Influence of gender on the onset and duration of rocuroniuminduced neuromuscular block. Biomed Pap Med Fac Univ Palacky Olomouc Czech Repub 2007; 151: 301-5.

18. Xue FS, Tong SY, Liao X, Liu JH, An G, Luo LK. Dose-response and time course of effect of rocuronium in male and female anesthetized patients. Anesth Analg 1997; 85: 667-71. 